I am one of those who might be an older adult, I have a complex and complicating medical history and I have numerous complexities, but I am not a complex person. Such sweeping categorisation can cause inadvertent offence when used in relation to patients.

A more appropriate title would be 'A guide to treatment planning for older adults with dental and medical complexities'.

S. Morganstein, by email

1. Geddis-Regan A, Walton G. A guide to treatment planning in complex older adults. Br Dent J 2018; 225: 395-399. https://www.nature.com/articles/ sj.bdj.2018.742 (accessed on 22 October 2018)

DOI: $110.1038 /$ sj.bdj.2018.982

\section{Associate specialists}

\section{The lost tribe}

Sir, I am currently a dental core trainee in a district hospital. My sessions are often under the direct supervision of an associate specialist in oral and maxillofacial surgery (OMFS), and in Orthodontics.

I am grateful for their vast clinical experience. I am in a district hospital and there is nothing much to do. I spend my days going to the gym and pondering why I've moved to a remote location. I remind myself that I am getting good experience.

During one particularly wet day, jogging on the treadmill and playing sudoku, a thought occurred which worried me.

An associate specialist working on the pre-2006 contract could have earned from $£ 38,836$ up to $£ 84,2401$ more if on-call. This was the case for dentists working in a maxillofacial and oral surgery department.

An associate specialist in OMFS has disappeared as a job title for dentists and replaced with 'speciality doctor'. The pay scale is from $£ 37,923$ to $£ 70,718^{11}$ The role of a speciality doctor in OMFS usually requires one to have two years' experience as a DCT in oral and maxillofacial surgery and MFDS/MJDF.

An orthodontist associate specialist, on a pre-2006 contract and top banding, might take a pay cut if he were to train to become a consultant, as the pay-scale starts from $£ 76,761$ up to $£ 103,490$. $^{2}$

If the orthodontist decided to retire, he/ she could be replaced with a 'speciality doctor' potential starting salary $£ 37,923$ or 'associate specialist' starting $£ 53,169,{ }^{1}$ or perhaps even a part-time consultant orthodontist and an orthodontic therapist.

I don't have a mortgage yet, due to the lowly DCT salary, but if I did, I would bet my mortgage that the DCT post I have will cease to exist in the future.

I worry that there are many associate specialists in OMFS and orthodontic departments working as educational and clinical supervisors for DCTs and they will soon be (or already are) the 'tribe of forgotten associate specialists'.

I am concerned the lack of consultant posts available for oral surgery will have a knock-on effect for our education and the running of the OMFS departments in some regions, particularly at district hospitals.

\section{A. Hassan, by email}

1. British Medical Association. 2018 'Pay scales for SAS doctors in England'. Available at https://www. bma.org.uk/advice/employment/pay/sas-pay-england (accessed 21 September 2018)

2. British Medical Association. 2018 'Pay scales for consultants in England'. Available at https://www.bma. org.uk/advice/employment/pay/consultants-pay-england (accessed 21 September 2018). DOI: 10.1038/sj.bdj.2018.983

\section{Oral and maxillofacial surgery}

\section{MaxFax training opens up the world of dentistry}

Sir, having come to the end of Year 1 DCT in oral and maxillofacial surgery, I would like to reflect on what a valuable experience it has been.

Coming out of foundation training it was difficult to know if I'd made the right decision to abandon my newly developed and (very nearly) honed skills in general practice to venture into the unknown world of maxfax, especially with the threat of 'deskilling' on the horizon.

However, despite this being a common concern voiced by many of my peers who chose to progress into practice, what I found was quite the opposite; my skillset has vastly expanded in a way which I feel will be invaluable in whatever career path I eventually pursue.

I chose DCT1 in OMFS to improve my oral surgery techniques, widen my knowledge of the management of medically compromised patients and get exposure to facial trauma and disease - reasons I'm sure are generic amongst other trainees in similar posts.

As it turned out, this was just a small part of what I was to gain. My ability to cope with and perform in stressful situations was tested right from the first day on call, where I learned that prioritisation and time management would be key.

My communication skills blossomed. I began to more fully appreciate the value of effective teamwork, whether between members of my own department, doctors from other specialities, ward staff or the A\&E department. Finding myself in new and varied settings made me tailor my approach to patient management according to the situation.

One aspect that I feel particularly grateful for is the knowledge that I will have the confidence and ability to manage more cases independently should I return to practice.

Having been on the receiving end of a number of questionable referrals and patients sent directly to the emergency department I know how frustrating it can be when something could have been dealt with more appropriately in practice. The thought of how some of my consultants would react would certainly make me think twice before submitting a referral in future!

While many remain of the opinion that maxfax is not relevant to dentistry, I would strongly argue the contrary.

I would encourage anyone contemplating a post in the specialty to seize the opportunity. I feel it has provided me with all the tools I might need to become a good clinician in whatever field I find myself. Not only that, I have had my eyes opened to the big wide world outside of the dental surgery where life or death situations are a daily occurrence.

As I go in to my second year of OMFS Dental Core training, I hope to continue to build to skills I have developed, and look forward to where it may lead me.

R. Unyolo, by email DOI: 10.1038/sj.bdj.2018.984

\section{Cosmetic dentistry}

\section{Facial aesthetic treatments and clinical and radiological implications}

Sir, cosmetic facial treatments are a rapidly developing area of clinical practice with increasing numbers of GDPs providing facial aesthetic treatments. As their popularity grows, more patients are now undertaking such procedures. We would, 